\title{
Determinants of Expressed Breast Milk Awareness Among Mothers in Siddharthnagar Municipality of Rupandehi District, Nepal
}

\section{Sigma Bhattarai ${ }^{1}$ and Chet Kant Bhusal ${ }^{2}$}

\begin{abstract}
${ }^{1}$ Department of Nursing, Universal College of Medical Science, Ranigaun, Bhairahawa, Nepal
${ }^{2}$ Department of Community Medicine, Universal College of Medical Sciences, Ranigaun, Bhairahawa, Nepal
\end{abstract}

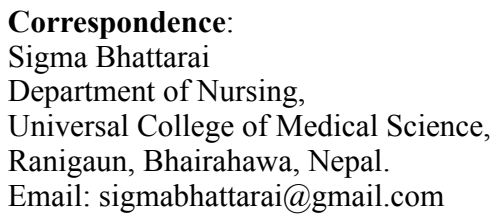

DOI: $10.3126 /$ jnps.v41i i2.31151

Submitted on: 2020-09-11

Accepted on: 2021-06-27

Acknowledgements: Researcher would like to extend gratitude to the concerned authority of Siddharthnagar municipality for granting permission to conduct the research. Researchers express their deep and sincere gratitude to all those experts for their valuable judgment, constructive feedbacks and enlightening suggestions throughout the study. Researcher owes a great deal and graceful thanks to all the respondents for their participation, cooperation, valuable time and information given as needed for this research study.

To cite this article: Bhattarai $\mathrm{S}$, Bhusal CK. Determinants Of Expressed Breast Milk Awareness Among Mothers in Siddharthnagar Municipality of Rupandehi District, Nepa. J Nepal Paediatr Soc. 2021;41(2):162-8.

\begin{abstract}
Introduction: Expressed breast milk is the practice of squeezing breast milk for the purpose of further use. Infant and young child feeding is very important in promoting healthy growth and development, particularly during the first two years of child's life. The awareness of mothers regarding expressed breast milk has a direct impact on the life of infants and feeding practices. The study aimed to find out possible determinants of awareness regarding expressed breast milk among mothers.
\end{abstract}

Methods: Descriptive cross-sectional study was conducted among 255 mothers from January 2020 to May 2020 by using probability simple random sampling technique. A validated and pre-tested semi-structured interview schedule was used. The data was collected data and analysed.

Results: Mean age of mothers was 26 years. $54.1 \%$ of the respondents had low awareness regarding expressed breast milk. After adjustment some of the variables such as age of respondents $(\mathrm{AOR}=0.03, \mathrm{CI}=0.01-0.08, \mathrm{p}<0.001)$, religion $(\mathrm{AOR}=0.36$, $\mathrm{CI}=0.14-0.99, \mathrm{p}<0.001)$ and educational status of respondents $(\mathrm{AOR}=4.40, \mathrm{CI}=1.72-11.26, \mathrm{p}<0.001)$, were significantly associated with level of awareness regarding expressed breast milk.

Conclusions: More than half of the mothers had low awareness regarding expressed breast milk. Age of the respondents, religion and educational status were found to be associated factors that influence mother's awareness regarding expressed breast milk. It is recommended to concerned authority to conduct awareness program regarding expressed breast milk among mothers.

Key words: awareness; expressed breast milk; mother

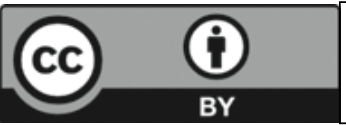

This work is licensed under creative common attribution 3.0 license 


\section{INTRODUCTION}

Exclusive breast feeding has massive health and socio-economic benefits for child, mothers as well as families. ${ }^{1,2}$ Evidence showed that maternal employment is the major cause for the termination of breastfeeding. ${ }^{3}$ Breast milk expression is the squeezing of milk from mother's breasts either by use of hand or with an efficient breast pump, so as to store it for future feeding of the baby. ${ }^{4}$ Expressed breast milk is a possible way of feeding child with breast milk in the absence of mother. ${ }^{5}$ Breast milk expression is important because the baby can have the benefits of breast milk even if mother is not available all the time. Expressed breast milk also helps to produce more milk, as expressing can boost the supply. It also helps to prevent from breast engorgement. Feeding expressed breast milk is best feeding for infants with feeding difficulty and infants in intensive care units. ${ }^{6}$

Under nutrition is estimated to cause 3.1 million child deaths annually or $45 \%$ of all child deaths. Optimal breastfeeding could save over 800000 under 5 child lives every year. ${ }^{5}$ A study on knowledge, attitude and intending practice of female undergraduates about breastfeeding in Nigeria shows $50.5 \%$ of respondents had knowledge about expressed breast milk. ${ }^{7}$ Another study on self-instruction module is effective in improving knowledge of mothers regarding expression and storage of breast milk in Pune, India shows more than half $(53.3 \%)$ of respondents didn't have knowledge about expressed breast milk. ${ }^{8}$

Adequate knowledge on breastfeeding, its expression and storage helps to reduce infant morbidity and mortality. However limited studies had been conducted to find out the reason of having low awareness about expressed breastfeeding. Thus this study was conducted to find out possible determinants of awareness regarding expressed breast milk among mothers.

\section{METHODS}

Cross-sectional descriptive study design was conducted among mothers in Siddharthnagar Municipality ward number 1, Rupandehi district, Province-5, Nepal. Total sample of 255 mothers of children under two years of age were selected by using probability simple random sampling technique. According to municipal office of Siddharthnagar Municipality, there are 700 under two year's children in Siddharthnagar Municipality ward number 1. By using Solvin formula sample size (255 samples) was calculated. With the help of Female Community Health Volunteers (FCHV) and community leader of Siddharthnagar municipality pre survey was done before data collection to find out the household of mothers with under two years children. Households having under two years children were numbered. After numbering of household, house number were selected through non replacement lottery method. This process was continued until sample reached to 255. Pretesting was done in Siddharthnagar Municipality ward number 7, Rupandehi district, Province-5, Nepal. Data were collected in four weeks period from March 20 to April 20, 2020 by using pretested semi-structured interview schedule. Ethical approval was obtained from Institutional Review Committee, Universal College of Medical Sciences Institutional Review Committee (UCMS/IRC/ 011/20). Administrative approval was obtained for data collection from concerned authority of Siddharthnagar Municipality. Written informed consent was obtained from each respondent by explaining the objectives of the study. Data was collected through pretested semi-structured interview schedule by reaching one by one mother of numbered household who were selected through non replacement lottery method.

The inclusion criteria were those mothers of children under 2 years of Siddharthnagar Municipality ward number 1, Rupandehi district, Province-5, Nepal and who are available during the data collection period. The exclusion criteria were those who were not willing to participate. The collected data were checked for completeness, coded and was analyzed using descriptive (frequency, percentage, mean and standard deviation) and inferential statistics (chi square, crude odds ratio, adjusted odds ratio) with Statistical Package for Social Sciences (SPSS) version 20.0.

\section{RESULTS}

Regarding background related characteristics of respondents $52.9 \%$ were of age greater than 25 
Table 1. Socio demographic characteristics of respondents $(n=225)$

\begin{tabular}{|c|c|c|}
\hline Variables & Frequency & $\%$ \\
\hline \multicolumn{3}{|l|}{ Age in years } \\
\hline Lesser than equal to 25 & 120 & 47.1 \\
\hline Greater than 25 & 135 & 52.9 \\
\hline $\begin{array}{l}\text { Mean age } \pm \mathrm{SD}= \\
26.225 .78\end{array}$ & & \\
\hline \multicolumn{3}{|l|}{ Caste } \\
\hline Brahmin, Chhetri & 42 & 16.5 \\
\hline Janjati & 42 & 16.5 \\
\hline Dalit & 50 & 19.6 \\
\hline Madhesi & 76 & 29.8 \\
\hline Muslim & 45 & 17.6 \\
\hline \multicolumn{3}{|l|}{ Religion } \\
\hline Hindu & 165 & 64.7 \\
\hline Christian & 45 & 17.6 \\
\hline Muslim & 45 & 17.6 \\
\hline \multicolumn{3}{|l|}{ Type of family } \\
\hline Nuclear & 150 & 58.8 \\
\hline $\begin{array}{l}\text { Others (joint and } \\
\text { extended) }\end{array}$ & 105 & 41.2 \\
\hline \multicolumn{3}{|l|}{ Educational status } \\
\hline Illiterate & 145 & 56.9 \\
\hline Literate & 110 & 43.1 \\
\hline \multicolumn{3}{|l|}{ Working status } \\
\hline Non working & 143 & 56.1 \\
\hline Working & 112 & 43.9 \\
\hline \multicolumn{3}{|l|}{ Age of index child } \\
\hline Lesser than equal to 1 & 129 & 50.6 \\
\hline$>1$ year & 126 & 49.4 \\
\hline \multicolumn{3}{|l|}{ Spouse education } \\
\hline Illiterate & 86 & 33.7 \\
\hline Literate & 169 & 66.3 \\
\hline \multicolumn{3}{|l|}{ Spouse occupation } \\
\hline Job holder & 146 & 57.3 \\
\hline Other than Job Holders & 146 & 57.3 \\
\hline
\end{tabular}

years, $29.8 \%$ were madhesis, $64.7 \%$ were Hindu, $58.8 \%$ were from nuclear family, $56.9 \%$ were illiterate, $56.1 \%$ were not involved in any work (job), 50.6\% had index child of age one and lesser than one. Likewise $66.3 \%$ of respondents' spouses were literate and $57.3 \%$ of respondents' spouses were jobholders (Table 1).

Regarding awareness on expressed breast milk, $60.4 \%$ of the respondents answered collecting
Table 2. Respondents' awareness regarding expressed breast milk $(\mathrm{n}=255)$

\begin{tabular}{|lrr|}
\hline Characteristics & Frequency & $\%$ \\
\hline $\begin{array}{l}\text { Meaning } \\
\quad \begin{array}{l}\text { Collecting breast milk for } \\
\text { further purpose }\end{array}\end{array}$ & 154 & 60.4 \\
$\begin{array}{l}\text { Importance } \\
\text { Can be fed in the absence }\end{array}$ & 198 & 77.6 \\
$\quad \begin{array}{l}\text { of mother } \\
\text { Helps to store extra milk }\end{array}$ & 62 & 24.3 \\
$\begin{array}{l}\text { Duration of breastfeeding } \\
\text { 2 years }\end{array}$ & 198 & 77.6 \\
$\begin{array}{l}\text { Considerations before expressing } \\
\text { breast milk }\end{array}$ & & \\
$\quad$ Wash hand properly & 238 & 93.3 \\
$\quad \begin{array}{l}\text { Daily shower and stay tidy } \\
\text { Clean areola to nipple with }\end{array}$ & 127 & 49.8 \\
boiled water & 66 & 25.9
\end{tabular}

Way of Expressing breast milk by hand

Hold breast in $\mathrm{C}$ shape

$114 \quad 44.7$

Squeeze nipple and areola

$67 \quad 26.3$

Best container for storing

Baby feeding bottle

$117 \quad 45.9$

Cleaning the container

Boiling

$\begin{array}{ll}230 & 90.2\end{array}$

$124 \quad 48.6$

Storage in room

Storage in room for 4

$18 \quad 7.1$

Storage in refrigerator

$161 \quad 63.1$

Storage in refrigerator for 72 hours

Storage in freezer

Storage in freezer for 3 months

Treating Expressed Breast Milk

Luke warm water

$121 \quad 47.5$

Container for feeding

Small bowl and spoon

106

41.6

Feeding once stored breast milk

$225 \quad 88.2$

Feeding once stored breast

Benefit to mother

Prevent breast

engorgement

Prevent mastitis

$\begin{array}{ll}48 & 18.8\end{array}$

Enhance milk supply

$99 \quad 38.8$

Prevent breast cancer

$98 \quad 38.4$

Benefit to baby

Easy to digest

$123 \quad 48.2$

Provide immunity to baby

$\begin{array}{rr}78 & 31\end{array}$

Protect against allergies

$81 \quad 31.8$

Increase baby's

$95 \quad 37.3$ 
Table 3. Respondents' overall level of awareness regarding expressed breast milk $(\mathrm{n}=225)$

\begin{tabular}{lcc|}
\hline Awareness level & Frequency & \% \\
\hline Low $(<14)$ & 138 & 54.1 \\
High $(\geq 14)$ & 117 & 45.9 \\
Total & 255 & 100 \\
Total Score $=30$ & Total Score $=30$
\end{tabular}

breast milk for further purpose as meaning of expressed breast milk, $77.6 \%$ answered can be fed in the absence of mother as importance of expressed breast milk and $77.6 \%$ answered duration of breastfeeding is two years. Likewise $93.3 \%$ of the respondent knew washing hand properly as consideration that should be taken before expressing breast milk, $44.7 \%$ of the respondent answered hold breast in $\mathrm{C}$ shape as way of

Table 4. Factors associated with level of awareness in bivariate and multivariate analysis

\begin{tabular}{|c|c|c|c|c|c|}
\hline \multirow[t]{2}{*}{ Characteristics } & \multicolumn{2}{|c|}{ Awareness Level (\%) } & \multirow[t]{2}{*}{ p-value } & \multirow[t]{2}{*}{ aCOR 95\%CI } & \multirow{2}{*}{$\begin{array}{c}\text { bAOR 95\% } \\
\text { CI }\end{array}$} \\
\hline & Low Awareness & High Awareness & & & \\
\hline
\end{tabular}

Age of Respondents

$<25$ years
$>25$ years

$14(11.7)$

$124(91.9)$

Ethnicity

$\begin{array}{lr}\text { Dalit } & 14(28.0) \\ \text { Non Dalit } & 124(60.5)\end{array}$

\section{Religion}

$\begin{array}{ll}\text { Hindus } & 76(46.1) \\ \text { Non Hindus } & 62(68.9)\end{array}$

\section{Types of family}

Nuclear

Joint and Extended

$$
76(50.7)
$$$$
62(59.0)
$$

\section{Educational status}

$\begin{array}{lr}\text { Illiterate } & 117(80.7) \\ \text { Literate } & 21(19.1)\end{array}$

\section{Spouse's Education}

Illiterate

Literate

$53(61.6)$

$85(50.3)$

\author{
$61(42.7)$
}

$77(68.8)$

Non Working

Working

\section{Spouse Occupation}

Other than Job Holder

Job Holders

$$
\begin{aligned}
& 86(78.9) \\
& 52(35.6)
\end{aligned}
$$

\section{Age of Index Child}

$\leq 1$ Year

$61(47.3)$

77 (61.1)

$>1$ Year

$\begin{aligned} 106(88.3) & \\ 11(8.1) & <0.001 *\end{aligned}$

$11(8.1)<0.001 *$

$36(72.0)$

$81(39.5)$

$<0.001^{*}$

$89(53.9)$

$28(31.1)<0.001 *$

$74(49.3)$

43 (41.0)

0.186

0.71

$(0.43-1.18)$

$(0.22-0.66)$

(0.14 - 0.99)

$28(19.3)$

$<0.001 *$

17.71

(9.44 - 33.23)

4.40

$89(80.9)$

33 (38.4)

84 (49.7)

0.086

1.59

(0.94 - 2.69)

82 (57.3)

$35(31.3)<0.001 *$

0.34

$(0.20-0.57)$

$(1.72-11.26)$

$23(21.1)$

1

6.76

$94(64.4)<0.001 *$

$(3.82-11.97)$

$(0.50-3.77)$

*Significant at $p<0.05,1=$ Reference category, ${ }^{a}$ Crude Odds Ratio, ${ }^{b}$ Adjusted Odds Ratio

$68(52.7)<0.027^{*}$

49 (38.9)

0.57

0.47

$(0.35-0.94) \quad(0.19-1.15)$ 
expressing breast milk by hand and $45.9 \%$ knew baby feeding bottle as best container for storing. Similarly $90.2 \%$ of the respondent answered boiling as method for cleaning the container, $47.5 \%$ knew expressed breast milk can be treated by luke warm water and $41.6 \%$ answered small bowl and spoon as container for feeding. In the same way $67.8 \%, 63.1 \%$ and $7.8 \%$ of the respondents answered expressed breast milk can be stored in room, refrigerator and freezer respectively. Likewise $88.2 \%$ answered once stored breast milk can be fed, $38.8 \%$ knew enhance milk supply as benefit of expressed breast milk to mother and $48.2 \%$ knew easy to digest as benefit of expressed breast milk to baby (Table 2).

Regarding respondents' overall level of awareness on expressed breast milk, $54.1 \%$ of the respondents have low awareness level and $45.9 \%$ have high awareness level (Table 3).

Regarding factors associated with level of awareness in bivariate and multivariate analysis, those variables which were found statistical significant with $p$ value lesser than equal to 0.05 in bivariate analysis, were entered into the multivariate regression analysis model which identified age of respondents, religion and educational status of women as associated factors with awareness regarding expressed breast milk. Mothers who were greater than 25 years were 0.03 times less likely $(\mathrm{AOR}=0.03, \mathrm{CI}=0.01-0.08)$ to have high level of awareness regarding expressed breast milk. The odds of having high awareness level regarding expressed breast milk were less among mothers who were from non Hindu (Muslim and Christians) religion ( $\mathrm{AOR}=0.36, \mathrm{CI}=0.14$ 0.99). Similarly, the odds of having high level of awareness regarding expressed breast milk increased 4.4 times $(\mathrm{AOR}=4.40, \mathrm{CI}=1.72$ 11.26) among mothers who were literate in comparison to their counterparts (Table 4).

\section{DISCUSSION}

The present study revealed that more than half $(54.1 \%)$ of respondents had low awareness regarding expressed breast milk which is in line with another study conducted in Kathmandu Nepal. ${ }^{9}$ However study conducted in Patan, Lalitpur, Nepal found lower portion (39.6\%) of the mothers had inadequate awareness regarding expressed breast milk. ${ }^{10}$ In contrast to this study, other studies such as study conducted in Hyderabad, India and Sokoto Nigeria found more proportion of the women $(64 \%)$ were less aware about expressed breast milk. ${ }^{11,12}$ This may be due to improvement in education activities, different methodology adopted and various study setting.

The study findings showed three-fifth of respondents were aware regarding meaning of expressed breast milk as collecting breast milk for further purpose which is not consistent with the another study conducted in Semnan, Iran where less than one-third of respondents had correct knowledge regarding collection breast milk. ${ }^{7}$ The present study revealed that $77.6 \%$ of respondents were aware about importance of expressed breast milk as can be fed in absence of mother which is not consistent to the study conducted in South Arabia which found $66.77 \%$ of respondents had correct knowledge regarding importance of expressed breast milk as can be fed in absence of mother. ${ }^{13}$ Similarly in contrast to this study, another study conducted in Turkey found higher proportion of mothers were aware that milk expression is perform in order to feed infant when baby is separated from mother. ${ }^{14}$ The present study found nearly about one-fourth of respondents were aware that expressed breast milk helps to store extra milk. This finding is not consistent to the study conducted in India which found high proportion of respondents had correct knowledge regarding importance of expressed breast milk as helps to store extra milk. ${ }^{8}$ The findings of the study showed $77.6 \%$ of respondents were aware about duration of breastfeeding as two years which is not consistent with the study conducted in Karnataka, India. ${ }^{15}$

Most of respondents in the present study were aware about washing hands properly, 25.9\% knew about cleaning areola to nipple, $49.8 \%$ knew about daily shower and being tidy as considerations before expressing breast milk. The finding is not consistent with the study conducted in Turkey. ${ }^{16}$ The present study revealed that less than half of respondents were aware about way of breast milk expression by hands as holding breast in ' $\mathrm{C}$ ' shape which is in line with another study conducted in Nigeria. ${ }^{12}$ The present study revealed that less than half of respondents were aware about best container 
for storing expressed breast milk as baby feeding bottle which is in line with the study conducted in Hyderabad, India. ${ }^{11}$

Nearly half of respondents in this study were aware about air drying the container to store expressed breast milk which is consistent with the study conducted in Turkey ${ }^{16}$. The study revealed that $7.1 \%$ of respondents were aware regarding storage of expressed breast milk in room temperature for 4 hours which is not consistent with the study conducted in Hyderabad, India which shows 34\% of respondents had correct knowledge regarding storage of expressed breast milk in room temperature for 4 hours. ${ }^{11}$ The findings of the study showed $5.5 \%$ of respondents were aware regarding storage of expressed breast milk in refrigerator for 72 hours, however another study conducted in Iran found higher proportion (11.8\%) of respondents had correct knowledge regarding storage in refrigerator for 72 hours. ${ }^{17}$ The present study found that $3.1 \%$ of respondents were aware regarding storage of expressed breast milk in freezer for 3 months, which is not consistent with the study conducted in Iran where $18 \%$ of respondents had correct knowledge regarding storage in freezer for 3 months. ${ }^{17}$ The study revealed that less than half of respondents were aware regarding treating the expressed breast milk in luke warm water before feeding. However, another study conducted in Turkey found higher proportion of respondents had correct knowledge regarding treating expressed breast milk in luke warm water. ${ }^{16}$ The findings of the study showed around two-fifth of the mothers were aware about best container for feeding as spoon and small bowl feeding which is in line with another study conducted in Sokoto, Nigeria. ${ }^{12}$ The present study found $11.4 \%$ of the respondents were aware about feeding previously stored and once fed milk again without restoring it within one to two hours, the result which is in contrast with the findings of the study conducted in Sokoto, Nigeria. 12

The present study revealed that $34.5 \%$ and $38.8 \%$ of respondents were aware about benefits of expressed breast milk to mothers as it prevents breast engorgement and enhances milk supply respectively. The findings of the study is not consistent with another study conducted in India where $62 \%$ mothers were aware that expressed breast milk prevents breast engorgement and 32\% were aware that it enhances milk supply. ${ }^{11}$ The present study revealed that $3.1 \%, 48.2 \%$ and $37.3 \%$ of respondents were aware about benefits of breast milk to baby as provides immunity to baby, easy to digest, increases intelligence respectively which is not consistent with the study conducted in India where higher proportion of mothers were aware about benefits of breast milk to baby as provides immunity to baby, easy to digest, increases intelligence respectively. ${ }^{11}$ Similarly nearly about one-third of the respondents were aware about benefits of breast milk to baby as prevents against allergies which is in line with another study conducted in India. ${ }^{11}$

In the present study statistical association was established between age of the mothers and awareness regarding expressed breast milk which is not consistent with several studies such as the study conducted in Patan Hospital Nepal and India. ${ }^{10,11}$ In the current study, mother's education was significantly associated with awareness regarding expressed breast milk which is also supported by several studies such as study done in Saudi Arabia and Singapore. ${ }^{18,19}$ Age of the index child in this study is found significantly associated with awareness regarding expressed breast milk in bivariate analysis which is in line with the study conducted in Sokoto, Nigeria. ${ }^{12}$

Our study is limited by the fact that it is a questionnaire based study conducted among a limited number of participants in a small part of the country. Hence, it shall be difficult to generalise our findings to the whole population. However, we are hopeful that our research would shed some light in the area of breast feeding and encourage other researchers to conduct larger studies involving relatively larger area.

\section{CONCLUSIONS}

The study concluded that more than half of the respondents have low awareness regarding expressed breast milk. Variables such as age, religion and educational status influence on mothers awareness regarding expressed breast milk. Awareness regarding expressed breast milk is significantly higher among mothers who were less than 25 years. Hindu and literate mothers were 
found to have high awareness regarding expressed

breast milk.

\section{REFERENCES}

1. WHO. World Health Organisation (WHO). Global strategy for infant and young child feeding. Geneva, Switzerland: WHO; 2003

2. Kramer MS, Kakuma R. The optimal duration of exclusive breastfeeding: a systematic review. Advanc Experi Miedicine and Biology. 2004;554:63-77. DOI: 10.1007/978-1-4757-4242-8_7

3. Cooklin AR, Donath SM, Amir LH. Maternal employment and breastfeeding: results from the longitudinal study of Australian children. Acta Paed. 2008;97(5):620-23. DOI: 10.1111/j.1651-2227.2008.00740.x

4. Chege P, Ndungu Z. Expressing breast milk: constraints among working lactating mother in Nairobi, Kenya. Int J Curr Adv Res. 2016;5(10):1397-99.

5. Mangalgi S, Sudheendra M. Assessment of knowledge regarding breastfeeding mothers in the immediate postpartum period. IJCH. 2017;4(2) 252-5. DOI: 10.32677/IJCH.2017.v04.i02.032

6. Labiner-Wolfe J, Fein SB, Shealy KR, Wang C. Prevalence of breast milk expression and associated factors. Pediatrics. 2008;122(2):63-8. DOI: 10.1542/peds.2008-1315h

7. Ogunba BO, Agwo E. Knowledge, Attitude and intending practice of female undergraduates about breastfeeding. African J Food, Agr, Nutr and Development. 2014;14(4):9039-54.

8. Shinde E, Samaj's M. Self-instruction module is effective in improving knowledge of mothers regarding expression and storage of breast milk. IJNH. 2015;1(3):193-202.

9. Pandey S. Awareness about expressed breast milk feeding among working mothers visiting a tertiary level hospital, Kathmandu. JKMC. 2019;8(2):60-5. DOI: 10.3126/jkmc.v8i2.28165

10. Lama M. Working mother's awareness and practice regarding feeding of expressed breast milk. JPAHS. 2019;6(2): 60-3. DOI:10.3126/jpahs.v6i2.27233

11. Rai S. Expressed breast milk: A less used option by working mothers of India. Int J Reprod Contracept Obstet Gynecol. 2017;6(7):2867-73. DOI: 10.18203/2320-1770.ijrcog20172603

12. Attahiru A, Awosan K, Oche M, Kaoje A, Yusuf T, Ango U. Breastfeeding Support and Determinants of Expressed Breast Milk Feeding Practice among Working Mothers in Sokoto, Nigeria Section: Community Medicine. Int J Cont Medical Research. 2018;5(8):1-8. DOI: 0.21276/ijcmr.2018.5.8.18

13. Alhabas MS. Breastfeeding among working mothers in Saudi Arabia. Theses and Dissertations 2016. Retrieved from https://scholarcommons.sc.edu/etd/3614

14. Col-Araz N, Aydin N, Tasdemir HS, Parlar-Kilic S. Breast milk expression knowledge of school of medicine and faculty of health sciences students. J Nurs Edu and Pract. 2013;3(10):19-25. DOI: 10.5430/jnep.v3n10p19

15. Divyarani D, Goudappa R. Knowledge, attitude and practices of breast feeding among post natal mothers. Int J of cont paediatrics. 2015;2(4):445-49.

16. Karanci G, Yenal K. Breastfeeding knowledge among working pregnant women in Turkey. Workplace Health \& Safety. 2014;62(4):143-8. DOI: 10.1177/216507991406200403

17. Karimi B, Sani MZ, Ghorbani R, Danai N. The pregnant mothers' knowledge about breastfeeding in Semnan, Iran. Middle East J Rehabil and Health. 2014;1(1):e20833. DOI: 10.17795/mejrh-20833

18. Qutah KM, Alsaleem SA, Najmi AA, Zabbani MB. Assessment of Knowledge and Practice about Self Expressed Breast Milk among Saudi Mothers in Jazan Region, KSA, 2016. JAMMR. 2019;29(10):1-11. DOI: 10.9734/jammr/ 2019/v29i1030132

19. Pang WW, Bernard JY, Thavamani G, Chan YH, Fok D, Soh S-E, et al. Direct vs. expressed breast milk feeding: Relation to duration of breastfeeding. Nutr. 2017;9(6):547. DOI:10.3390/nu9060547 